best approach that could be adopted. An interesting discussion is given of current British and American thinking on these materials.

Three chapters on structural properties and design present a wealth of experience and technical information with appropriate references. In the chapter on 'a laboratory approach to design' the author states that he is now in favour of a method specification, but points out that selection of a compliance density is still necessary to assess the degree to which laboratory specimens at the mix design stage have to be compacted.

The nature of cement-treated pavements is discussed in Chapter 10 and the author concludes that pavements having bases of cement-treated materials should be analysed on the assumption that they are rigid materials.

Chapters 11,12 and 13 deal with the subject of cracks. Chapter 11 discusses the factors influencing cracking. In Chapter 12, attitudes to cracking are considered. Both chapters contain much valuable information, although to some extent they have been upstaged by the papers at the 1986 International Conference on Bearing Capacity of Roads and Airfields. In particular, Mayhew and Potter, from their survey of 970 lane $\mathrm{km}$ of trunk roads and motorways, stated that transverse cracking is not a major factor in determining overall pavement performance. Their paper also confirmed the author's view stated elsewhere that single-layer construction should be used for cementtreated materials.

Novel approaches to methods of dealing with cracks are discussed interestingly in Chapter 13.
Chapter 15 summarizes the behaviour of cementtreated pavements in service, and contains information gleaned from experimental roads in the UK (Alconbury Hill), USA, South Africa, Germany and Holland. Reference is also made to the PIARC survey. The conclusion to this chapter draws on a Californian study of cement-treated bases on 175 projects built between 1950 and 1962 which shows that sections with the highest compressive strength had the longest maintenance-free life.

Empirical and analytical approaches to pavement design are the subject of Chapters 16 and 17 respectively. The next chapter presents a simplified semianalytical approach to pavement design in some detail, based on a two-layer analysis. It takes into account the nature of cement-treated bases and sets out fairly the difficulties and benefits of this approach.

Construction of cement-treated layers is dealt with comprehensively in three chapters and in Chapter 24 the author gives a summary of work with wet lean materials and also the use of recycled pavement materials.

In the final chapter the author makes a plea for a move away from the empirical approach to cementtreated pavements, and sees the future for cementtreated materials as having tremendous possibilities.

This book has such wealth of information contained within it that it must remain a standard work on cement-treated pavements for many years, and the author is to be congratulated for his comprehensive coverage of the subject.

L. J. CARROLL

\title{
Steel fiber concrete
}

US-Sweden joint seminar (NSF-STU), Stockholm, 3-5 June 1985

\section{Editors: Surendra P. Shah and Åke Skarendahl}

London and New York, Elsevier Applied Science Publishers, 1986. $246 \times 172 \mathrm{~mm}$. Typewritten, hardback. ISBN 1851660437. pp. 526. Price $£ 50 \cdot 00$.

The growing understanding of steel-fibre-reinforced concrete as an engineering material is demonstrated by the collection of 25 seminar papers presented in this book. The Preface identifies five currently successful applications of steel fibre concrete (shotcrete, pavements and overlays, precast products, protective concrete structures and furnace linings) and these are all discussed to a greater or lesser extent. A note of regret is sounded in many of the papers that the advantages of the material for these and other purposes is not more widely appreciated and that its practical appli- cation is not more widespread. Some of the authors point out the 'chicken and egg' situation in which engineers are reluctant to use the material in the absence of codes, standards and an established track record, which cannot be readily established unless the material is more widely used.

The papers very in their scope and depth: a number are good review papers whereas some are rather narrow and do no more than describe particular applications or systems. Of the review-type papers, that on steelfibre-reinforced shotcrete by V. Ramakrishnan is the 
best, but other worthwhile ones include a lengthy 'catalogue' of applications in the field of bridge decks and pavements (G. Hoff) and a rather more technical review of the same area (E. K. Schrader). Unfortunately the references are omitted from this latter paper. Other reviews deal with current applications (R. F. Zollo), micromechanical modelling (J. A. Mandel), flexural behaviour (V. S. Gopalaratnam and S. P. Shah), toughness (C. D. Johnston), use of steel fibres for shear reinforcement and ductility (G. B. Batson), bridge decks and building floors (R. N. Swamy) and durability (M. Schupack).

Some current commercial applications are described, including the Besab reinforced steel-fibre-reinforced concrete system, wet process shotcrete, tilt-up sandwich panels, the Ekebro AB fibre shotcrete system, precast products in Scandinavia, selection of steel fibre type and content, slurry-infiltrated-fibre-reinforced concrete (SIFCON), and advanced tunnel support. Aspects covered in the remaining papers are fracture toughness (A. Hillerborg), fracture resistance (S. P. Shah and Y. S. Jenq) and steel fibre concrete for structural elements (M. Lorentsen). Finally, three papers deal with performance criteria and quality assurance.

The good impression created by the attractive and durable binding of the book is unfortunately spoilt on opening it. The typed papers from the seminar are reproduced with, apparently, little attempt being made to achieve consistency in terms of style, typeface or layout. A few are of reasonable quality, but too many are barely adequate, especially in the line drawings and half tones, and would have benefitted from rigorous editing. On the positive side, an index with about 500 terms is included.

Overall, the book is a useful compilation especially for the review papers, but it is only likely to be essential reading for the specialist in the field.

J. N. CLARKE

\title{
Fracture toughness and fracture energy of concrete
}

\author{
Proceedings of the International Conference on Fracture Mechanics of Concrete, \\ Lausanne, Switzerland, October 1-3, 1985 \\ Developments in Civil Engineering, Volume 18
}

\section{Editor: F. H. Wittmann}

\begin{abstract}
Amsterdam and New York, Elsevier Science Publishers B.V., 1986. $242 \times 168 \mathrm{~mm}$. pp. xiv, 699. Reproduced typewriting, illustrated, hardback. ISBN 0444427333 (Vol. 18). Price: Dfl. 350-00 (US\$ 155.50).
\end{abstract}

The International Conference on Fracture Mechanics of Concrete held in Lausanne in 1985 marked the end of the activities of the RILEM Technical Committee on Fracture Mechanics of Concrete (50-FMC). The first aim of the committee was achieved with the publication of a comprehensive state-of-the-art report on the fracture mechanics of concrete in 1983 (Fracture Mechanics of Concrete, Developments in Civil Engineering, Vol. 7, Elsevier, 1983). This earlier volume taken together with the book currently under review form an impressive resource for all those interested in fracture of concrete.

The book contains 72 papers sub-divided into the following chapters:

Fracture process and mechanics of crack growth

Damage theory

Computer simulation and numerical studies

Influences on strength

Fracture process zone

Fracture toughness

Fracture energy

Strain rate effects

Fibre reinforced concrete
Applications and reinforced concrete

The cracking and fracture of concrete: An annotated bibliography, 1982-1985.

The contributors are drawn from 18 countries and, although several well-known researchers in this field are absent from the list, the papers give a good overview of current research into the fracture of concrete. As is inevitable with such a wide authorship, some papers suffer from transliteration. It is not possible in a review of this type to do justice to all the research included in the book and consequently a few general comments will have to suffice.

It is interesting to note the changes in emphasis between the volume produced by the same committee in 1983 and the current book. These changes are also reflected in the annotated bibliographies included in both books. The earlier research dealt largely with the question of whether fracture mechanics, and in particular linear elastic fracture mechanics (LEFM), was truly applicable to concrete. Because of the inconsistencies and contradictions in the experimental studies reported, the question was not properly answered. The latter book contains a general consensus that 